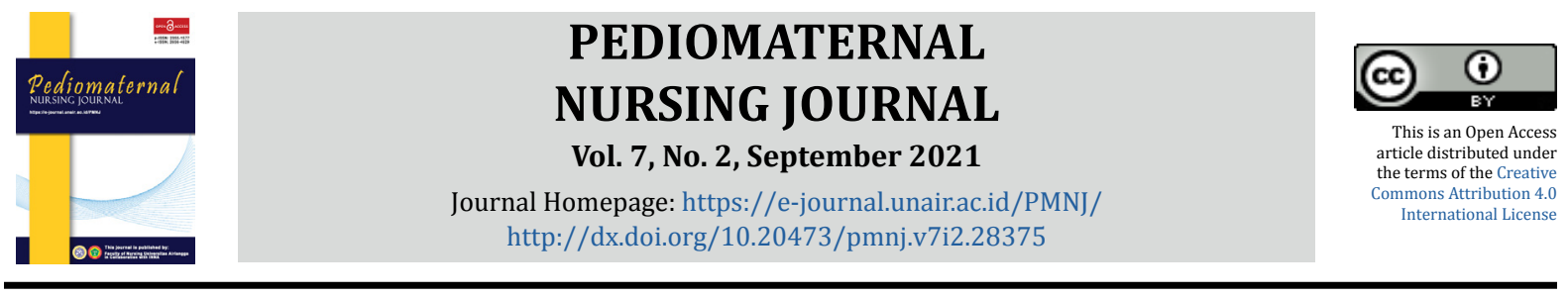

Original

\title{
A Qualitative Evaluation Study of The Infant and Young Child Feeding Counselling
}

\section{Fitria Nurwulansari $^{1 *}{ }^{\oplus}$, Deni Kurniadi Sunjaya ${ }^{2}{ }^{\oplus}$, Dida Akhmad Gurnida ${ }^{3}{ }^{\circledR}$, Dewi $^{\circ}$ Marhaeni Diah Herawati² ${ }^{\oplus}$, Ieva Baniasih Akbar $^{4}(\mathbb{D}$}

\footnotetext{
${ }^{1}$ Department of Midwifery, Poltekkes Kemenkes Surabaya, Surabaya, Indonesia

${ }^{2}$ Department of Public Health, Faculty of Medicine, Universitas Padjadjaran, Bandung, Indonesia

${ }^{3}$ Department of Medical Nutrition, Faculty of Medicine, Universitas Padjadjaran, Bandung, Indonesia

${ }^{4}$ Faculty of Medicine, Universitas Islam Bandung, Bandung, Indonesia
}

\section{ARTICLE HISTORY}

Received : July 16, 2021

Revised : August 25, 2021

Accepted : September 7, 2021

Published : September 15, 2021

\section{KEYWORDS}

evaluation study; counselling; infant

\section{CORRESPONDING AUTHOR}

*Fitria Nurwulansari fitrianurwulansari1993@gmail. com

Department of Midwifery, Poltekkes Kemenkes Surabaya, Surabaya, Indonesia

Cite this as:

\begin{abstract}
Introduction: The Infant and young child feeding (IYCF) counselling program is an international strategy to improve IYCF practices in the community. This study aimed to explore the implementation of the program through the logic model approach.

Methods: A qualitative method was employed for this evaluation study. Fifteen participants were selected by purposive random sampling, and data collection was conducted by in-depth interview, focus group discussion, observation, and document study. Data were processed from transcription, reduction, coding, categorizing to data interpretation and assessed by content analysis.

Results: IYCF training is a cascading training and a combination of adult and fun learning that effectively produces a mixture of counsellors who can provide counselling using the counselling cards. However, the gap in the number of cadre counsellors and the target of counselling, as well as the limited time, low financial support, over workload, and inadequate supervision, resulted in poor recording and low numbers of clients who had been exposed to counselling. Nevertheless, this counselling has a positive effect on maternal knowledge and attitude. Still, the existence of traditional community practices, family and environmental factors are barriers to the implementation of proper IYCF practices.

Conclusion: IYCF counselling effectively improved IYCF practices, so it has to be continued with strengthening the number of counsellors, recording and supervision activities. Changing strategy in counselling by involving other adult household members like grandmother or neighbours are explicitly targeted for more effective in improving the practices of infant and young child feeding.
\end{abstract}

Nurwulansari, F., Sunjaya, D, K., Gurnida, D, A., Herawati, M, D., \& Akbar, I, B. (2021). A Qualitative Evaluation Study of The Infant and Young Child Feeding Counselling. Pediomaternal Nurs. J., 7(2), 109-119. Doi: http:// dx.doi.org/10.20473/pmnj.v7i2.28375

\section{INTRODUCTION}

The period from conception until the first two years of a child's life is a golden period that determines the quality of life. Assuring adequate nutrition during this 
period is fundamental for developing each child's full human potential (Dewey, 2016). Therefore, WHO (World Health Organization) recommends early breastfeeding initiation practice, exclusive breastfeeding from birth to 6 months of age, introduce complementary foods at six months of age while breastfeeding, and on-demand breastfeeding until two years of age or beyond (Kathyrn Dewey, 2001).

Data from the Indonesian Demographic and Health Survey (IDHS) in 2017 showed that only 52 per cent of 0-5 months infants were exclusively breastfed. However, the coverage of children who continue to breastfeed until the age of 2 years was slightly decreased from 55 per cent in 2012 to 54 per cent in 2017. As many as 43 per cent of children under two months were fed using bottles with pacifiers (Badan Pusat Statistik, 2017).

Feeding practices are strongly associated with child nutritional status (Ruel \& Menon, 2002). Factors contributing to poor quality and insufficient quantity in child feeding practices are the low maternal education and lack of necessary knowledge and information, particularly during the complementary feeding period (Armar-klemesu et al., 2000; Shi and Zhang, 2011). A systematic review suggested that educational interventions effectively positively affect caregivers' knowledge and behaviours to improve complementary feeding practices and child nutrition (Shi \& Zhang, 2011).

In 2012, Indonesia collaborated with WHO and United Nations Children's Fund (UNICEF) and the Indonesian Millennium Challenge Account (IMCA) to provide Infant and Child Feeding (IYCF) training. Infant and young child feeding training are one of several activities oriented towards improving the nutritional status of pregnant women and children in the Community Based Health and Nutrition Project (CBHNP) (Indonesian MCA, 2014). Infant and young child feeding training are carried out in cascade by training health workers to become facilitators who will train cadres to implement IYCF counselling in the real community. This training aims to improve the knowledge and skills of the cadres as the spearhead of service in the village then it will help improve the nutritional status in the community. In addition, through IYCF training, it is expected that cadres have counselling skills in dealing with the problem of feeding infants and children (Kemenkes, 2014).

Sukabumi Regency is a pilot project for the IYCF training program that consists of 47 sub-districts. While those who met the criteria for IYCF training are 22 sub-districts, one of the sub-districts is Cireunghas. Infant and young child feeding counselling have been implemented in the community since 2014, but there are minimal rigorously evaluated. An evaluation study is particularly useful when new interventions are being developed and considered for replication or scalling up. A logic model is defined as a graphical representation of how a program is intended to work and links outcomes with processes and the theoretical assumptions of the program.

A logic model framework for community nutrition education showed that inputs are the resources available for the planning, implementation, and evaluation of projects such as human resources, funding, facilities, equipment, and curricula. Activity is the educational program component. Output is the direct product or results of program activities. Outcomes describe the changes or impacts that occurred because of the program outputs. A framework for the community nutrition education logic model showed that shortterm outcomes and indicators were defined to reflect increased awareness, knowledge, and skills. Medium-term outcomes and indicators were deemed those that reflected action taken and changed behaviours. Long-term effects and indicators were tied to personal health and nutritional status. An evaluation study was conducted to find out the impact of the program and how it might be expanded to other areas and contexts (Clapham et al., 2017). This study aims to explore the core components of the IYCF counselling program with a logic model approach.

\section{METHOD}

\section{Study Design}

This study used a qualitative method with a content analysis approach to explore the input, activity, output and outcome of the infant and young child feeding counselling.

\section{Population, Samples, and Sampling}


The population of this study were in Cirenghas Sub-district, Sukabumi Regency, East Java that included IYCF counsellors (midwives and community cadres) in Cireunghas Primary Health Care, nutrition health worker as facilitators IYCF counselling, leader of Primary Health Care, national facilitator IYCF counselling and IYCF program manager of the Public Health Office in Sukabumi Regency.

Qualitative data were collected from 15 participants and selected using the purposive random sampling technique in the working area of Cirenghas Public Health Service. Among five villages, two counsellor cadres per village were purposively selected for focus group discussion. Focus group discussions $(\mathrm{n}=9)$ and six in-depth interviews were conducted. The in-depth interview was conducted among two midwives as IYCF counsellors, one nutrition health worker as facilitator IYCF counselling, one leader of Primary Health Care, one national facilitator IYCF counsellor, and IYCF program manager of the Sukabumi Public Health Office. Participants were recruited based on the criteria following the objectives to be achieved. The criteria used to recruit participants were; cadres or midwives who have a certificate of IYCF counsellor; the important person in training (facilitators); leadership position such as the leader of Primary Health Care and IYCF program manager of the Public Health Office.

\section{Instruments}

1. The data collection instrument that used in this research, namely:

2. Researcher: As an instrument, researchers examine documents related to the implementation of IYCF counselling.

3. Interview guidelines: Researchers use tools in the form of semi-structured written questions to guide in-depth interviews and notes field.

4. Voice recorder: As a recording device, a voice recorder is used to record the process of interviews in verbal conversations between researchers and participants.

\section{Procedure}

The data collection was carried out by visiting the research subject to explain the objectives, benefits and procedures in research. Subjects willing to participate in the study were given a sheet of consent to be signed (informed consent). Primary data were collected through in-depth interviews, focus group discussion, observation, and document study using guidelines to analyze input components, processes, outputs, and outcomes. The indepth interview used guidelines that have been made for IYCF counsellors (village midwives and cadres), nutrition health workers, IYCF facilitators, head of Public Health Care and manager of IYCF training program and FGD guidelines for cadre counsellors.

All interview and focus group discussion was held in the place and time that was convenient for the participants. During collecting data, a field note was taken. The in-depth interviews were recorded and taking of 30-60 minutes, and the focus group discussion was audio-recorded for about 60 90 minutes. Besides, secondary data obtained from document studies include document counselling report books or visit books.

\section{Data Analysis}

After collecting the data, data were transcribed and analyzed. Besides, the field notes were rewritten again, and the records were repeatedly listening to understand more deeply the response and the meaning of the conversation with participants. Data were analyzed using manual thematic content analysis through a general approach with the following steps; transcription, reduction, coding, categorizing and determining theme. Transcription: data were transcribed as the results of interviews, focus group discussion, and observation. Then data were compiled into different types depending on the source of information. Reduction: researcher read the whole data and deeply interpreted general ideas. The researcher wrote general notes or ideas from the obtained data. Coding: researcher segmented sentences into specific categories and terms. It was categorizing: The researcher classified similar codes in categories based on interpretation. Determining theme: The researcher determined the theme by re-grouping the categories that have been produced in the form of articles.

\section{Data Quality Assurance}

\section{Credibility}

pISSN: 2355-1577 • eISSN: 2656-4629 | http://e-journal.unair.ac.id/PMNJ 
Data credibility testing was done by participants and methods triangulation and discussion with peers. Participants triangulation was carried out by collecting data on various participants for a deeper understanding of the implementation of IYCF counselling. Methods triangulation used in-depth interviews, focus group discussion, observation, and document study. Before the data collection, the professionals evaluated in-depth interviews, focus group discussions, observation, and document study guidelines.

\section{Transferability}

Transferability was done by describing the research context and assumptions that were central to the research. Then, the researcher made a report by providing detail, clear, systemic, and reliable descriptions.

\section{Dependability}

To assess the dependability of the research taken by conceptualizing the research plan, data collection, and interpretation by involving someone competent with a doctoral degree in Public Health at Universitas Padjadjaran. In addition, member checking was conducted by returned the preliminary findings to the participants to correct errors and challenge what was perceived as wrong interpretations.

\section{Confirmability}

Assessing the quality of research results with proven truth based on data that has been collected and reported in the results notes. Peer debriefing exposed the preliminary findings to a doctoral degree in Public Health at Universitas Padjadjaran.

\section{Ethical Clearance}

Before data collection, permission was obtained from Universitas Padjadjaran Ethical Review Committee with the Number: 203/ UN6.KEP/EC/2018.

\section{RESULTS}

\section{Inputs}

The component of inputs identifies all of the resources that are necessary for the program to operate. For example, the IYCF counselling model identifies five types of information: human resources, IYCF kits, funding, IYCF training, and IYCF SS training.

\section{Human resources}

This study found that IYCF counsellor is a mixture of counsellors from a health professional and the community itself, namely community cadre. Twenty-seven counsellors consist of 20 community cadres, five midwives, one nutrition health worker and one health promotion worker. Cireunghas District consisted of 53 public health, care which was spread in 5 villages. This showed a gap between the number of cadre counsellors and counselling targets so that not all targets have been exposed to IYCF counselling.

\section{IYCF aids}

Successfully IYCF counselling is supported by the availability of IYCF aids. The IYCF aids consist of IYCF training modules adopted from UNICEF and counselling aids, including counselling cards, booklets, and leaflets. The counsellors said that the counselling cards was beneficial in the implementation of counselling.

"Not wrong, it helps. If we were just talking a lot about it, sometimes it would be forgotten. But, if we give them a picture... It's easy to remember, pleasant to use it." (Informant 10)

Implementation of the IYCF counselling is only based on IYCF training modules. There is no service flow in the performance of IYCF counselling. The availability of the flow of IYCF counselling services is still following the flow of public services. Clients who have been given counselling were only pregnant women and mothers who had children with nutritional problems counselling so that not all targets in the group of 1000 first days of life were exposed to IYCF counselling.

\section{Funding}

At the time of the pilot project, IYCF training was funded by IMCA. Then, further training was funded by Regional Development Funds to those targets in non-Community-Based Health and Nutrition Project (CBHNP) areas. In addition, the counsellors said that there was no financial support for implementing IYCF counselling because the counselling was a part of the work of health workers, and it was also the same for cadre counsellors. 
"I went around using my own money. I am asking for fees. There's also no money for some food" (Informant 3)

There had been no policy or special attention to financial support for the counsellors, especially cadre counsellors, it is likely to have an impact on counsellor loyalty in preserving IYCF counselling.

\section{IYCF training}

IYCF training was carried out in stages to produce all cadres who were spread in Indonesia. Facilitators of IYCF counselling training were obtained from a training process conducted for six days (total 48 hours of study) with training material from the Ministry of Health adopted from UNICEF, while training to produced IYCF cadre counsellors was conducted for three days. The competencies acquired and possessed by each IYCF counsellor provide responsibility and confidence in conducting IYCF counselling. Cadres said that there was a fear of being wrong when gave giving information to mothers. However, this IYCF training explained how to counsel mothers so that the counsellor becomes aware and confident in providing counselling. The informant also had a new understanding of counselling as the statement below:

"Counselling is... I knew before that counselling is socialization. But now I have learned that counselling is when we have to face each other, one by one, the eyes must be straight, the body is aligned, so there should be no obstructions. We don't have to look around at the clock, and we have to focus on the mother." (Informant 5)

Participants said that IYCF training was not like other training that only sat at the table. Participants and facilitators sat down in the same land, so they made an atmosphere of well-togetherness. The program manager said that even though they were sitting without a chair, participants appreciated the facilitators and positioned themselves as participants as they should be. The combination of adult and fun learning provided an excellent atmosphere for doing something, not tense, and not boring because when it was saturated, or a session was too long, the facilitators would invite the audience for standing, singing, and even dancing. IYCF training can be used as a pioneer training model for replication in other trainings. It was like the participants and facilitators said that IYCF training was excellent.

\section{IYCF supportive supervision training}

The next training series was the IYCF Supportive Supervision (SS) Training conducted for three days for the primary health care level facilitators. The IYCF SS training aims to increase the capacity of facilitators in conducting IYCF counselling activities. In Sukabumi District, this training was carried out in 2017 which 46 participants attended. However, the existing constraints were IYCF SS training was not evenly distributed to all primary health care facilitators. This was due to the limited time and funds available for training.

\section{Process}

\section{IYCF counselling}

IYCF counselling could be done at posyandu (an integrated service post in the community area), primary health care, midwifes' clinic, and client' homes. Creating a cosy atmosphere was important to make a comfortable atmosphere in counselling to achieve the goals of counselling. This study found that there were still a lot of mothers who came to the primary health care were only briefly given information about feeding infants and children. Even some mothers were not given IYCF counselling. Counsellors said that they did not provide IYCF counselling to mothers who were not asking questions and not complaining about feeding problems, then the time constraints, and the double tasking undertaken by counsellors. Also, at the posyandu, some counsellors only provided counselling to mothers who had experienced difficulties in feeding. Mothers who did not ask questions or experienced problems were only weighed the baby as usual. Cadre counsellors made home visits more often so she could continually make visits (continuity of care) to clients to evaluate counselling meetings before, remembering that the target of IYCF counselling is a group of 1000 first days of life that is ranging from pregnant women to mothers who have two years old children.

Infant and young child feeding




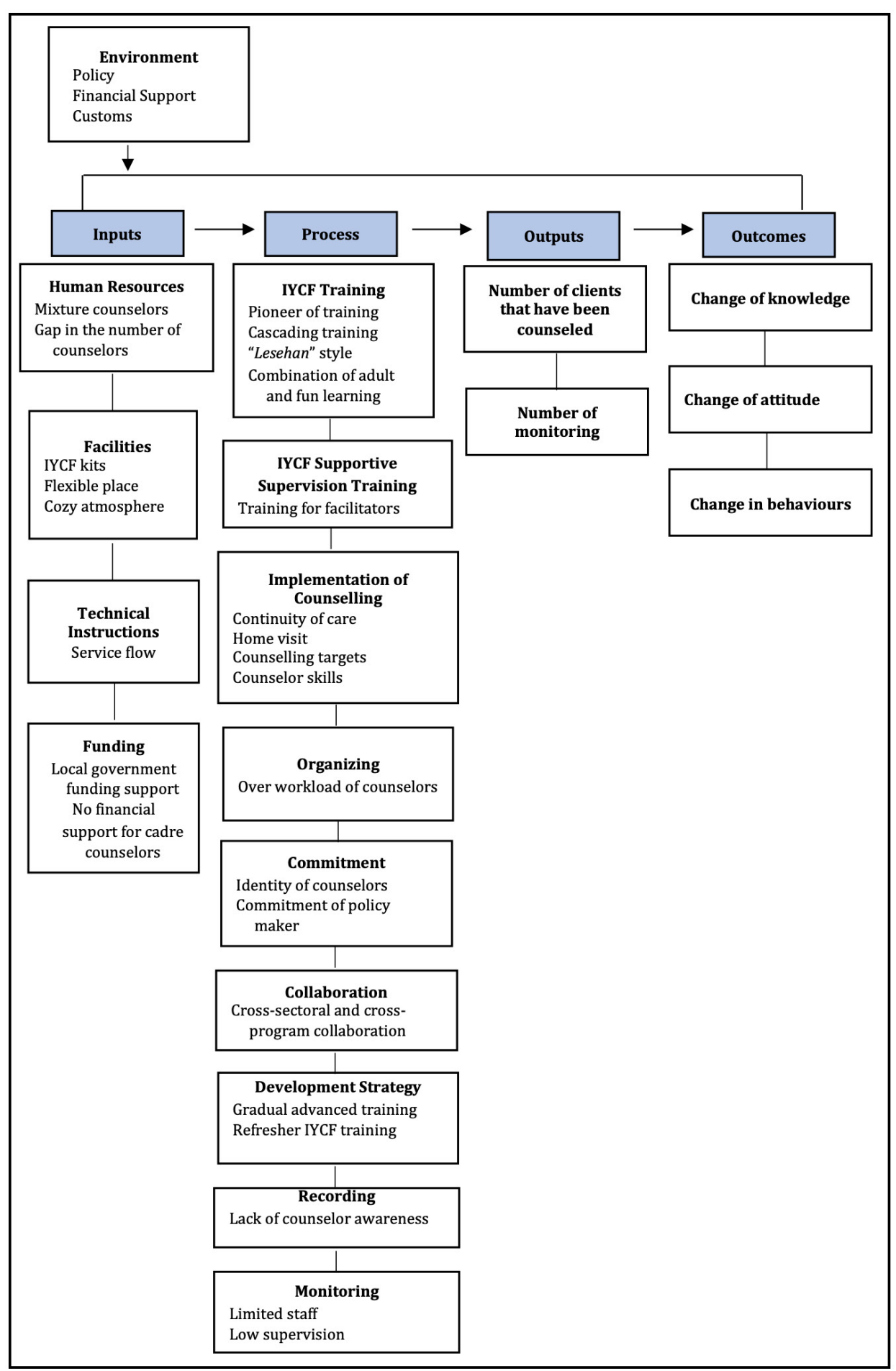

Figure 1. Results of the evaluation study on the implementation of IYCF counselling program

counselling implemented in Cireunghas Subdistrict is a one-on-one counselling process, so the counsellors should be concerned about communication skills and appropriate counselling steps to achieve the goals of counselling.

"So, for example, if the mothers have been concluded, say that 'oh ... I'm wrong in this' So, actually in IYCF counselling, the mothers who finally determine their problem. They continue to solve the problem. We just show the pictures on the card counselling. Then, they answered. It's turned back to them. Then, we review again how the conclusion is, what to do next. In the end, we reschedule 


\section{for the next meeting..." (Informant 12)}

In general, counsellors had performed communication skills well and used IYCF feedback sheets. The counsellors had the role of helping the clients until the clients understood what they did in the next to overcome IYCF problems.

\section{Recording}

Recording of IYCF counselling implementation was documented in the form of a Follow-up Plan format. Participants said that for the first six months after the training was still being recorded using the format. However, due to the lack of monitoring and no obligation to report the follow-up plan format, the counsellor' motivation began to decline in the recording. In addition, the midwife counsellors said that too many monthly reports had to be done, so they forgot to record the clients who had been counselled. In general, midwives only wrote clients who had been counselled in their register books in their clinics.

\section{Supervision}

The supervision activities had not been run optimally. For example, the IYCF counselors stated that supervision from facilitators of primary health care and public health offices were still minimal.

“... because of the lack of human resources for monitoring, they can't control all the counsellor's activities. In addition, It's also because of the tasks and programs themselves. They are easy to be forgotten." (Informant 15)

Supervision was conducted once in 2017, along with the implementation of the IYCF Supportive Supervision Training. At that time, facilitators at the primary health care level supervised the midwives and cadre counsellors. However, the program manager stated that there were no routine and comprehensive supervision of all counsellors in the Sukabumi District due to the limited human resources or the IYCF monitoring team.

\section{Outputs}

The output of IYCF counselling was obtained from the document review results by checking the document's completeness and seeing the documentation of the IYCF counselling implementation and the effects of interviews with counsellors and facilitators. The number of clients counselled was the output of IYCF counselling, and the amount of monitoring was the output of the IYCF Supportive Supervision Training. The coverage of IYCF counselling programs in the Cireunghas Sub-district had not been reached the target yet, one of which could be seen from the number of clients who had been counselled by only 9.5 percent of the target of mothers who had children 6-23 months. Nevertheless, the number of clients was far enough compared to the number of IYCF counselling targets.

\section{“... I did counselling, but not be recorded ..." (Informant 7)}

"... It has been forgotten. I usually marked it in my clinic register, to which has been given counselling. Because a lot of reports, so I did forget again and again... "(Informant 10)

The statement showed that counselling is often done but does not record correctly. However, the counsellors knew the people who had been given counselling because generally, the clients who were given counselling were the target of counselling in their village. In addition, formal monitoring was done just at once so that the counsellor's motivation to record was not.

\section{Outcomes}

Participants stated that the mother's response to IYCF counselling varied. However, generally, mothers were more understanding after had been given IYCF counselling.

“... There are some changes, there are some still, there is such a variety... most of them are quite a lot of changes, but if it's not, usually if the mother works, so the caregivers are the grandmother. And the grandmother doesn't want to bother ... "(Informant 10)

Counsellors said that the problem which is so difficult to change in feeding infants and 
children in Cireunghas Subdistrict is exclusive breastfeeding, especially for working mothers who left their children with their families or other caregivers. Cultural or traditional factors are still an obstacle. Babies aged $<6$ months are given honey, water, or start to be given a portion of food. The participants said that even though the mother understood and wanted to provide baby and child food as recommended, but not the same as caregivers such as her grandmother, her father, or her neighbours, such as the following statement:

“... Most of them did it. I was suspicious. Sometimes if I asked, the mother said yes to exclusive breastfeeding. But I saw her child was given a date by her neighbours. So I came to the mother and asked, but she said she didn't know anything. It showed that when the mother wants to practice feeding weel, but it has been disturbed by others ..." (Informant 3)

Mothers who didn't work and tend to feed their children according to the recommendations, children were still got inappropriate feeding behaviours from their environment. Therefore, environmental and family factors significantly affected the success of proper infant and child feeding practices.

\section{DISCUSSION}

Infant and young child feeding counselling is an innovative strategy that increases knowledge and attitude toward IYCF. Implementation of IYCF practices in Indonesia is supported by Government Regulation No. 33 in 2012 about the provision of milk, which stated that early breastfeeding must be initiated for the newborn baby for at least 1 (one) hour. Every mother who gives birth must give exclusive breastfeeding. Also, according to Indonesian Ministry of Health Regulation No. 25 in 2014 about Baby Health Services, stated that provision of complementary food is provided from the age of 6 (six) months; and breastfeeding continued for 2 (two) years (Government Regulation No. 33 in 2012 about the Provision of Milk, 2012; Indonesian Ministry of Health Regulation No. 25 in 2014 about Baby Health Services, 2014). The implementation of these policies in the era of decentralization in Indonesia should proceed concurrently and harmoniously where the central government issues policies and local governments provide support.

The local government supports IYCF counselling in the fulfilment of human resources, IYCF kits, funding, implementation of IYCF training and its counselling. The government has facilitated the implementation of IYCF training to produce end-user in the form of a mixture of counsellors consisting of nutrition health workers, midwives, and community cadres. Community cadres are the closest person to the community, so they are a key person in improving the ability of each family to feed infants and children as recommended (Kemenkes, 2014). In addition, midwives are also important as the central health worker in the village within more education than cadres. Therefore, either the community cadres or midwives can establish good partnerships in improving IYCF behaviours in their community. However, gaps between the number of cadre counsellors and the counselling targets caused un-optimal counselling implementation that counsellors prioritize only mothers with problems. The other things include limited budget funds for the performance of continuing training gradually and IYCF Supportive Supervision training, lack of attention to financial support, especially for cadre counsellors, difficulty to create a cosy atmosphere in counselling are the problems that cause not optimal components of the IYCF counselling implementation process yet.

IYCF training and a set of IYCF kits are considered very good so that they can be used as a pioneer in the implementation of the following training model in Indonesia. The cascading training strategy is effective in producing cadre counsellors spread throughout Indonesia. The cascading training model reflects good planning for this program. In addition, the lesehan style, which is making a warmer atmosphere and enhancing rapport (good relations) between participants and facilitators, and a combination of adult and fun learning, is successfully effective to achieve training goals. Training participants feel the benefits and valuable experiences. IYCF Training produces counsellors who can give IYCF information well enough to mothers or caregivers by using a variety of IYCF kits. However, there are limited time and 
workload that affect the quantity and quality of counselling. The implementation of IYCF Supportive Supervision training that has not been evenly distributed has caused minimal supervision. The supervision activities aim to monitor counsellor retention and decrease knowledge and skills development over time so that it can identify refreshing needs. However, lack of attention to cadre refreshing needs, intersectoral and inter-program coordination and collaboration, and less optimal supervision that results in the output of IYCF counselling have not reached the target. A study by Kohli and Chadha showed that counsellors who have received training could not communicate the messages they want to convey to clients, so routine refresher training is needed to improve counsellor communication skills (Kohli \& Chadha, 2017). Refresher training can also enhance cadre's motivation in giving information to mothers or caregivers (Rahmawati et al., 2019). In addition, a counsellor is not expected to convey a message but also can bring changes in IYCF practices.

According to Yawson et al., the low number of health workers who have received training, weak implementation of government policies, lack of intersectoral coordination and collaboration cause problems in optimizing nutrition interventions (Yawson et al., 2017). Policymakers need to pay more attention to the IYCF practice improvement program as a form of support for both housewives and working mothers (Gupta et al., 2019). Inter-sectoral collaboration, supportive behaviours of leaders and facilitation team were important factors contributing to the program's implementation. The combination and harmonization of all these factors may lead to the sustainable personal, institutional and professional changes that are donated to gains child nutrition (Havemann et al., 2012)

Behavioural change is the expected outcome of the IYCF counselling program. A study by Semahegn et al. showed that mothers who started breastfeeding before the age of 6 months were caused by a lack of mother's knowledge (Agumasie Semahegn, Gezahegn Tesfaye, 2014). Generally, in the family, the person who plays an important role in decision-making for IYCF practices is the mother (Cunningham et al., 2021), but it turns out that a study by Firdausya and Hardini found that some grandmothers told the mothers to give food to their babies when they were under six months old (Firdausya \& Hardini, 2020). However, this study showed that mothers who have good IYCF knowledge and attitude towards appropriate IYCF practices have not been successful in implementing IYCF practices according to recommendations because neither caregivers nor grandmothers do not necessarily have the same positive knowledge and attitudes as well as mothers. The low grandmother education had caused mothers to continue practising false IYCF practices, as the results of a study by Karmacharya et al. in Nepal showed that grandmothers' good knowledge about IYCF translated into mothers' good knowledge so that they played a role in optimal feeding practices (Karmacharya et al., 2017). In addition, qualitative studies in Ethiopia by Mekonnen et al. showed that the factors that most often affect the IYCF practices are sociocultural influences, traditional community practices, and economic factors (Mekonnen et al., 2018). Mother's education and occupation factors also can affect infant and young child feeding practices by mother, so that counsellors must pay special attention to mothers with low social status (Khan et al., 2017).

Changing strategies to increase social support from families and communities to improve IYCF behaviours is the most important key in educational interventions. As the IYCF program, in addition to IYCF counselling, there are also IYCF support group discussions. However, this activity has not been carried out in Cireunghas Sub-district. The IYCF support group consists of mothers, caregivers and other family members who share their personal experiences and provide support to others to promote the behaviours IYCF according to the recommendations. Also, women have to express their ideas and will, so women have empowerment during support group meetings (Lamstein, 2017). A systematic review by Manikam et al. in Bangladesh about administering complementary feeding showed that behavioural change interventions to deal with local cultural beliefs are needed to improve optimal complementary feeding practices (Manikam et al., 2017). In addition, this study showed that family members could influence the course of giving complementary

pISSN: 2355-1577 • eISSN: 2656-4629 | http://e-journal.unair.ac.id/PMNJ 
feeding. The intervention must also be directed to the broader community and relatives, not only to parents. The group meeting facilitates participants to reflect on their experiences, doubts, difficulties, existing beliefs/habits, and other information about IYCF (Kemenkes, 2014). The IYCF support group discussion also aims to provide peer support as emotional assistance and information about IYCF. Lamstein recommended that in the support group The success of appropriate IYCF practices requires support from the central and regional governments, Health Service Facilities and Health Workers, communities and families. The limitation of this study is that the researcher did not interview the clients who have been given IYCF counselling due to limited time and funds.

\section{CONCLUSION}

Infant and young child feeding counselling in the community were shown to be an innovative and effective program for improving IYCF practices, so it has to be continued with strengthening the number of counsellors, recording and supervision activities. Changing strategy in counselling by involving other adult household members like grandmother or neighbours are also explicitly targeted for more effective in improving IYCF practices. Further research is needed to determine changes in knowledge, attitude, and behaviours of IYCF on mothers who have been given IYCF counselling.

\section{ACKNOWLEDGMENT}

We would like to acknowledge Universitas Padjadjaran, College of Midwifery and Public Health, for the assistance of undertaking this research. We would also like to express our gratitude to study participants and supervisors.

\section{CONFLICT OF INTEREST}

The authors declare that there is no conflict of interest.

\section{REFERENCES}

Agumasie Semahegn, Gezahegn Tesfaye, A. B. (2014). Complementary feeding practice of mothers and associated factors in Hiwot Fana Specialized Hospital, Eastern
Ethiopia. Pan African Medical Journal, 8688, 1-11. https://doi.org/10.11604/ pamj.2014.18.143.3496

Armar-klemesu, M., Ruel, M. T., Maxwell, D. G., Levin, C. E., \& Morris, S. S. (2000). Community and International Nutrition Poor Maternal Schooling Is the Main Constraint to Good Child Care Practices in Accra 1. October 1999, 1597-1607.

Badan Pusat Statistik. (2017). Survey Demografi dan Kesehatan Indonesia 2017. 60. https://doi.org/10.1111/ j.1471-0528.2007.01580.x

Clapham, K., Manning, C., Williams, K., O’Brien, G., \& Sutherland, M. (2017). Using a logic model to evaluate the Kids Together early education inclusion program for children with disabilities and additional needs. Evaluation and Program Planning, 61, 96-105. https://doi.org/10.1016/j. evalprogplan.2016.12.004

Cunningham, K., Nagle, D., \& Singh, S. (2021). Associations between parents' exposure to a multisectoral programme and infant and young child feeding practices in Nepal. 17(January), 1-12. https://doi. org/10.1111/mcn.13143

Dewey, K. G. (2016). Review Article Reducing stunting by improving maternal, infant and young child nutrition in regions such as South Asia : evidence, challenges and opportunities. 12, 27-38. https://doi. org/10.1111/mcn.12282

Firdausya, T. J., \& Hardini, D. S. (2020). The Correlation between Mothers' Breastfeeding Pattern and Stunting among Toddlers. Pediomaternal Nursing Journal, 6(2), 108. https://doi. org/10.20473/pmnj.v6i2.19943

Foundation, W. K. K. (2014). W.K. Kellogg Foundation Logic Model Development Guide.

Government Regulation No. 33 in 2012 about the provision of milk, (2012).

Gupta, A., Suri, S., Dadhich, J. P., Trejos, M., \& Nalubanga, B. (2019). The World Breastfeeding Trends Initiative: Implementation of the Global Strategy for Infant and Young Child Feeding in 84 countries. In Journal of Public Health Policy (Vol. 40, Issue 1). https://doi. org/10.1057/s41271-018-0153-9

Havemann, K., Pridmore, P., Tomkins, A., \& 
Garn, K. D. (2012). What works and why? Evaluation of a community nutrition programme in Kenya. 16(9), 1614-1621. https://doi.org/10.1017/ S1368980012004880

Indonesian Millenium Challenge Account. (2015.). Community based health and nutrition to reduce stunting.

Indonesian Ministry of Health Regulation No. 25 in 2014 about Baby Health Services, (2014).

Karmacharya, C., Cunningham, K., \& Choufani, J. (2017). Grandmothers' knowledge positively in $\mathrm{fl}$ uences maternal knowledge and infant and young child feeding practices. 20(12), 2114-2123. https://doi.org/10.1017/ S1368980017000969

Kathyrn Dewey. (2001). Guiding Principles for Complementary Feeding of the Breastfed (PAHO and WHO). Pan American Health Organization and World Health Organization, 18-25. https://doi. org/10.1017/S1368980011002485

KEMENTERIAN KESEHATAN REPUBLIK INDONESIA. (2014). Modul Pelatihan Konseling: Pemberian Makan Bayi dan Anak. 21.

Khan, G. N., Ariff, S., Khan, U., Habib, A., Umer, M., Suhag, Z., Hussain, I., Bhatti, Z., Ullah, A., Turab, A., Khan, A. A., Garzon, A. C., Khan, M. I., \& Soofi, S. (2017). Determinants of infant and young child feeding practices by mothers in two rural districts of Sindh, Pakistan: A cross-sectional survey. International Breastfeeding Journal, 12(1), 1-8. https://doi.org/10.1186/ s13006-017-0131-z

Kohli, S., \& Chadha, R. (2017). Knowledge and Counselling Skills of Community Health Workers for Promotion of Optimal Infant and Young Child Feeding (IYCF) Practices: A Review. International Journal of Health Sciences and Research, 7(10), 240-248.

Lamstein, S. A. (2017). Women's empowerment in Nigeria: baseline data from an evaluation of the Community Infant and Young Child Feeding ( C-IYCF ) Counselling Package. The Lancet Global Health, 5, S29. https://doi.org/10.1016/ S2214-109X(17)30136-5

LYDIA C. MEDEIROS, PHD, RD1; SUE NICHOLSON BUTKUS, PHD, R. ;, HELEN
CHIPMAN, PHD, RD, LN3; RUBY H. COX, PHD, RD4 ; LARRY JONES, P. ; \& DEBORAH LITTLE, E. (2005). A Logic Model Framework for Community Nutrition Education. J Nutr Educ Behav, 37, 197-202.

Manikam, L., Robinson, A., Kuah, J. Y., Vaidya, H. J., Alexander, E. C., Miller, G. W., Singh, K. K., Dawe, V., Ahmed, S., Lingam, R., \& Lakhanpaul, M. (2017). A systematic review of complementary feeding practices in South Asian infants and young children: the Bangladesh perspective. 1-13. https://doi.org/10.1186/s40795017-0176-9

Mekonnen, N., Asfaw, S., Mamo, A., Mulu, Y., \& Fentahun, N. (2018). Barriers and facilitators of child-feeding practice in a small sample of individuals from Gozamin District, Northwest of Ethiopia : a qualitative study. 1-7.

Rahmawati, S. M., Madanijah, S., Anwar, F., \& Kolopaking, R. (2019). The effectiveness education of counselling of infant and young child feeding as intensive to improve counselling performance of Posyandu cadres in Bogor, Indonesia. International Journal of Community Medicine And Public Health, 6(6), 2280. https://doi.org/10.18203/2394-6040. ijcmph20192138

Ruel, M. T., \& Menon, P. (2002). Community and International Nutrition Child Feeding Practices Are Associated with Child Nutritional Status in Latin America: Innovative Uses of the Demographic and Health Surveys 1, 2. October 2001, 1180-1187.

Shi, L., \& Zhang, J. (2011). Recent evidence of the effectiveness of educational interventions for improving complementary feeding practices in developing countries. Journal of Tropical Pediatrics, 57(2), 91-98. https://doi.org/10.1093/tropej/ fmq053

Yawson, A. E., Amoaful, E. O., Senaya, L. K., Yawson, A. O., Aboagye, P. K., Mahama, A. B., \& Selenje, L. (2017). The lancet series nutritional interventions in Ghana: a determinants analysis approach to inform nutrition strategic planning. 1-8. https://doi.org/10.1186/s40795-0170147-1 